absorbing mechanisms (mainly bone) to attenuate and dampen the applied forces. In favour of this theory are the greater bone density in patients with osteoarthrosis of the hip and the rarity of the disease in patients who have fractured the upper end of the femur and who usually have osteoporosis. ${ }^{21}$ The same process may well account for the low prevalence of osteoarthrosis in a late review of patients with anterior poliomyelitis affecting the legs. ${ }^{22}$ Byers made an important contribution when he showed a histological distinction (in necropsies) between "limited alterations" and progressive disease. ${ }^{23}$.35 It was limited alterations that were found in the femoral head in the areas of habitual non-use by Bullough et al, ${ }^{26}$ who believed that the areas in the dome of the hip came into excessive contact with the head as the incongruity of the acetabulum diminished with age. This set up a progressive alteration in the head, which ultimately reacted on the acetabulum.

Further evidence in favour of a mechanical explanation of osteoarthrosis is the location of lesions in the patellofemoral joint. These correspond ${ }^{2}{ }^{28}$ to the contact areas of angles of flexion of the knee between 40 and 80 -the angles at which the peak loads occur. But this brings us back to the question: Why don't the joints of all people show degenerative changes? In some patients there is an obvious predisposing causeindeed, of 327 patients whose osteoarthrotic hips had been removed at surgery, Solomon ${ }^{29}$ believed he could identify a cause in all but 27 . In others an inflammatory element may be prominent, ${ }^{30}$ possibly provoked by apatite crystals, ${ }^{31}$ though whether this is a primary or secondary phenomenon is not clear. Muir's explanation ${ }^{4}$ of the predisposition of some people to develop osteoarthrosis is that individuals vary considerably in the amounts and topographical distribution of collagen, chondroitin sulphate, and keratan sulphate in the articular cartilage. ${ }^{32} 33$

These questions are not only of academic interest: they have important implications for the prevention of the disease, for the development of drugs to halt its progress, and even for the type of surgery best suited to individual patients. At present mechanical factors seem to be important in the production of osteoarthrosis, but an explanation solely on the basis of wear and tear has become too simple.

\footnotetext{
1 Sokoloff, L, The Biology of Degenerative Foint Disease. Chicago, University of Chicago Press, 1969.

2 Freeman, M A R, Adult Articular Cartilage. London, Pitman, 1973.

${ }^{3}$ Wright, V, Clinics in Rheumatic Diseases, 1976, 2, No 3.

- Muir, H, Annals of the Rheumatic Diseases, 1977, 36, 199.

${ }^{5}$ Pond, M J, and Nuki, G, Annals of the Rheumatic Diseases, 1973, 32, 387.

${ }^{6}$ Bollet, A J, and Nance, J L, Fournal of Clinical Investigation, 1966, 45, 1170.

${ }^{7}$ Mankin, H J, and Thrasher, A Z, fournal of Bone and foint Surgery, 1975, 57A, 76.

${ }^{8}$ Adams, I D, Clinics in Rheumatic Diseases, 1976, 2, 523.

${ }^{9}$ Burke, M J, Fear, E C, and Wright, V, Annals of the Rheumatic Diseases, 1977, 36, 276

1" Murray-Leslie, C F, Lintott, D J, and Wright, V, Annals of the Rheumatic Diseases, 1977, 36, 327.

11 Brodelius, A, Acta Orthopaedica Scandinavica, 1960 1961, 30, 309

12 Pellingrini, P, Nibbio, N, and Piffanelli, A, Archispedale S Anna di Ferrara, 1964, 17, 879

${ }^{13}$ Solonen, K A, Annals Chirurgiae et Gynaecologiae Fenniae, 1966, 55, 176.

14 Radin, E L, Paul, I L, and Rose, R M, Lancet, 1972, 1, 519.

15 Jackson, J P, British Medical fournal, 1968, 2, 525.

16. Goldin, R H, et al, Annals of the Rheumatic Diseases, 1976, 35, 349.

17 Minns, R J, Steven, F S, and Hardinge, K, Fournal of Pathology, 1977, 122, 63.

1* Weightman, B O, Freeman, M A R, and Swanson, S A V, Nature, 1973,
} 244, 303.
${ }^{19}$ Johnson, G, Dowson, D, and Wright, V, Proceedings of the 3rd Leeds-Lyon Symposium on Tribology, 1977, in press.

2" Radin, E L, Bulletin of the Rhe'umatic Diseases, 1976, 26, 862.

2 Foss, M L V, and Byers, P D, Annals of the Rheumatic Diseases, 1972, 31, 259.

2.2 Glyn, J H, et al, British Medical fournal, 1966, 2, 739.

23 Byers, P D, Contepomi, C A, and Farkas, T A, Annals of the Rheumatic Diseases, 1970, 29, 15.

24 Byers, P D, Contepomi, C A, and Farkas, T A, Annals of the Rheumatic Diseases, 1976, 35, 114

2.5 Byers, P D, Contepomi, C A, and Farkas, I A, Annals of the Rheumatic Diseases, 1976, 35, 122

26 Bullough, P G, Goodfellow, J, and O'Connor, J J, Fournal of Bone and foint Surgery, 1973, 55B, 746 .

2- Meachim, G, and Emery, I H, Annals of the Rheumatic Diseases, 1974, 33, 39.

* Seedhom, B B, Biomechanics of Patello-Femoral ()steoarthrosis. Workshop on Models of Osteoarthrosis, 1977, in press.

29 Solomon, L, fournal of Bone and foint Surgery, 1976, 58B, 176

30 Ehrlich, G E, Fournal of the American Medical Association, 1975, 232, 157.

Dieppe, P A, et al, Lancet, 1976, 1, 266.

32 Muir, H, Maroudas, A, and Wingham, J, Biochimica et Biophysica Acta, $1969, \mathbf{1 7 7}, 494$

33 Kempson, G E, et al, Biochmica et Biophysica Acta, 1973, 297, 456.

\section{Names of drugs}

Our reluctance to consider printing the proprietary names of drugs in $B M \mathcal{F}$ articles has stimulated further correspondence this week ( $p$ 1024). There is a good case for including the name of the specific preparation used in reports of side effects and in trials of new drugs, since a proprietary or non-proprietary "equivalent" may differ in the preservatives used or in bioavailability. The real problems arise with teaching and review articles in the Medical Practice section, which may mention a score or so of commonly used drugs on a single page. While we recognise the irritation that may be caused our readers by our description of all these drugs simply by their approved or generic names, there is no satisfactory alternative. We tried to provide a glossary of the manufacturers' names a few years ago, but it proved dauntingly difficult. What do we do, for example, when an article refers to prednisolone? MIMS lists Codelcortone, Codelsol, Cordex, Cordex Forte, Delta-Cortef, Deltacortril, Deltastab, Di-Andreson, Precortisyl, Prednesol, and Sinitisone, and a further group of various methylprednisolone preparations. Similar lists need to be made for compounds such as phenobarbitone, and indeed any widely prescribed drug that is no longer covered by patent. New proprietaries are introduced each month, others are withdrawn; but pharmaceutical firms are rightly indignant if their latest product is omitted from such lists. About one-quarter of $B M \mathcal{F}$ readers live outside Britain, and drugs used in all parts of the world (such as ampicillin or propranolol) may have different proprietary names in each continent.

In practical terms, most doctors have a British National Formulary on their desks, which includes a reasonably comprehensive glossary of proprietary drugs with their approved names. A similar list is published by the British Pharmacopoeia Commission. The range of drugs prescribed by any individual is remarkably narrow, and once the decision is taken to "think generic" surely the effort required is small. 